\title{
Experimental Study on Ballistic Resistance Test of AA2519/AA1050/ Ti6Al4V Laminate According to STANAG 4569 Level 2
}

\author{
Marcin WACHOWSKI ${ }^{1}$, Ireneusz SZACHOGLUCHOWICZ ${ }^{1}$, Lucjan SNIEZEK ${ }^{1}$, \\ Volodymyr HUTSAYLYUK ${ }^{1}$, Wojciech KOPERSKI ${ }^{2}$
}

\author{
${ }^{1}$ Faculty of Mechanical Engineering, Military University of Technology, gen. W. Urbanowicza 2 str., \\ 00-908 Warsaw, Poland, \\ ${ }^{2}$ Faculty of Mechatronics and Aviation, Military University of Technology, gen. W. Urbanowicza 2 \\ str., 00-908 Warsaw, Poland, \\ E-mail: ${ }^{1}$ marcin.wachowski@wat.edu.pl
}

\begin{abstract}
The aim of this paper is to investigate the ballistic properties of laminates made of light alloys under various configuration and thickness. The laminates were obtained by explosive welding method. Composite components are aluminum alloy AA2519 and titanium alloy Ti6A14V with the aluminum alloy AA1050 as intermediate layer. The paper describes the influence of the bullet impact energy on the structure of the panel, depending on the configuration of the laminates: thickness of the layers and the applicated heat treatment. Ballistic resistance tests were carried out in accordance with the standards STANAG 4569 Level 2. The results of the research were compared to the ballistic resistance of typical material used for ballistic shields production.
\end{abstract}

KEY WORDS: explosive welding, cladding, laminates, aluminum, titanium, ballistic resistance, STANAG standard

\section{Introduction}

An important factor for the development and reliability of technical objects exposed to bullets is adequately high ballistic resistance and, at the same time, the lowest density. Typical metallic ballistic shields are supporter for the objects and additional shields depending on the type of threat. The high weight of the armored steel often used to produce ballistic shields leads to limit the protected elements in military construction [1]. Additionally, steels shields are used as a monolithic shields which protect the construction against the impact of small bullets with the lower range of velocity. To protect the most sensitive elements of the construction, Whipple shields are typically used as a passive ballistic shields located in exposed zones [2,3]. The type and thickness of these boards varies depending on the degree of hazard and exposure of the place exposed to damage. Currently, the most promising ballistic shields are explosively welded laminates made of aluminum alloy AA2219 and titanium alloy Ti6A14V [4].

The explosively welded laminate made of base materials: aluminum alloy AA2519 (AlCuMgMn $+\mathrm{ZrSc}$ ) and the titanium alloy Ti6A14V were described only in few publications [7,8]. Previous works included examination of layered composite material Ti6A14V/AA1050/AA2519 indicate present of diffusion layer A13Ti between titanium and aluminum alloy which provide high mechanical properties including high ballistic resistance [5-7]. It was assumed that such laminate is characterized by unique properties that combine the beneficial properties of titanium alloy, aluminum alloys (high strength, high plasticity and low density) and intermetallic phases Ti-Al (high hardness and stiffness) [8-11]. Properties of the laminate change depending on the applied heat treatment [12].

Different properties of the base materials have an influence on energy dissipation in materials during ballistic resistance test. A significant is also thickness of the layers and their order relative to the projectile shot direction [13]. Energy absorption by the layers of the laminate is manifested on only by the rapid deceleration of the projectile, but also by the level of fragmentation of the laminate. In layered materials, there is also a risk of delamination of the material [14].

Corresponding author. Tel.: 0048261839245

E-mail address: marcin.wachowski@wat.edu.pl 


\section{Materials and Methods}

Explosive welding process was performed by EXPLOMET High-Energy Techniques Works. Chemical composition and mechanical properties of base materials are shown in Tables 1-3.

Table 1

Mechanical properties and chemical composition of the Ti6Al4V alloy

\begin{tabular}{cccccccccccc}
\hline \multicolumn{10}{l}{ Mechanical properties } & \multicolumn{10}{c}{ Chemical composition $(\mathbf{w t}$ \%) } \\
\hline $\mathrm{Rp} 0,2(\mathrm{MPa})$ & $\mathrm{Rm}(\mathrm{MPa})$ & $\mathrm{A}(\%)$ & $\mathrm{O}$ & $\mathrm{V}$ & $\mathrm{Al}$ & $\mathrm{Fe}$ & $\mathrm{H}$ & $\mathrm{C}$ & $\mathrm{N}$ & $\mathrm{Ti}$ \\
\hline 950 & 1020 & 14 & $<0.20$ & 3.5 & 5.5 & $<0.30$ & $<0.0015$ & $<0.08$ & $<0.05$ & rest \\
\hline
\end{tabular}

Mechanical properties and chemical composition of the AA2519 alloy

\begin{tabular}{llllllllllll}
\hline \multicolumn{1}{l}{ Mechanical properties } & \multicolumn{1}{c}{ Chemical composition (wt \%) } \\
\hline $\mathrm{Rp} 0,2(\mathrm{MPa})$ & $\mathrm{Rm}(\mathrm{MPa})$ & $\mathrm{A}(\%)$ & $\mathrm{Si}$ & $\mathrm{Fe}$ & $\mathrm{Cu}$ & $\mathrm{Mg}$ & $\mathrm{Zn}$ & $\mathrm{Ti}$ & $\mathrm{V}$ & $\mathrm{Zr}$ & $\mathrm{Sc}$ \\
\hline 312 & 335 & 6.5 & 0.06 & 0.08 & 5.77 & 0.18 & 0.01 & 0.04 & 0.12 & 0.2 & 0.36 \\
\hline
\end{tabular}

Mechanical properties and chemical composition of the AA1050 alloy

Table 3

\begin{tabular}{llllllllllll}
\hline \multicolumn{1}{l}{ Mechanical properties } & \multicolumn{7}{l}{ Chemical composition $($ wt \%) } \\
\hline $\begin{array}{l}\mathrm{Rp} 0,2 \\
(\mathrm{MPa})\end{array}$ & $\begin{array}{l}\mathrm{Rm} \\
(\mathrm{MPa})\end{array}$ & $\begin{array}{l}\mathrm{A} \\
(\%)\end{array}$ & $\mathrm{Fe}$ & $\mathrm{Si}$ & $\mathrm{Zn}$ & $\mathrm{Mg}$ & $\mathrm{Ti}$ & $\mathrm{Mn}$ & $\mathrm{Cu}$ & $\mathrm{Al}$ \\
\hline 120 & 115 & 3 & 0.4 & $<0.25$ & $<0.05$ & $<0.05$ & 0.03 & $<0.05$ & $<0.05$ & rest \\
\hline
\end{tabular}

Heat treatment included annealing for 2 hours at $530^{\circ} \mathrm{C}$ with rapid cooling in water and then aging for 10 hours at $165^{\circ} \mathrm{C}$. Heat treatment was applied to improve the strength properties of the material by precipitation hardening of AA2519.

The observation of the produced laminates were carried out with the use of the Scanning Electron Microscope (SEM) Jeol JSM-6610 equipped with energy-dispersive x-ray spectroscopy (EDS) and back-scattered electron (BSE) detector. SEM was used to observe the cross section through the components of the laminates. Observations were performed using acceleration voltage $20 \mathrm{kV}$. The cross-sections were prepared by cutting the samples in direction perpendicular to laminates surfaces with precision diamond saw. Before structural examinations samples were subjected to the metallographic preparation involving grinding on $\mathrm{SiC}$ papers with granulations of 240, 600, 1200, 2400 and in sequence, polishing with diamond suspensions $3 \mu \mathrm{m}$ and $1 \mu \mathrm{m}$.

Ballistic resistance tests were performed on the both of base materials (AA2519 and Ti6Al4V) and panels made of laminates in different conditions (before and after heat treatment). Ammunition used in tests was projectile BZ rifle cartridge 7,62x39 mm according to the class III STANAG 4569 (Tab. 4.). The energy of cartridge in the moment of impact is 1300-2300 J. Tests were performed according to the standard STANAG 4569 Level 2 (Fig. 1,2.). Rifle 7.62 mm model 1944 was placed on the bench in order to ensure proper trajectory of the projectile flight. Proper mounting of the arms and putting the barrel axis relative to the sample was performed before each test. During the shot the distance between the weapon and sample was equal to $2.5 \mathrm{~m}$.

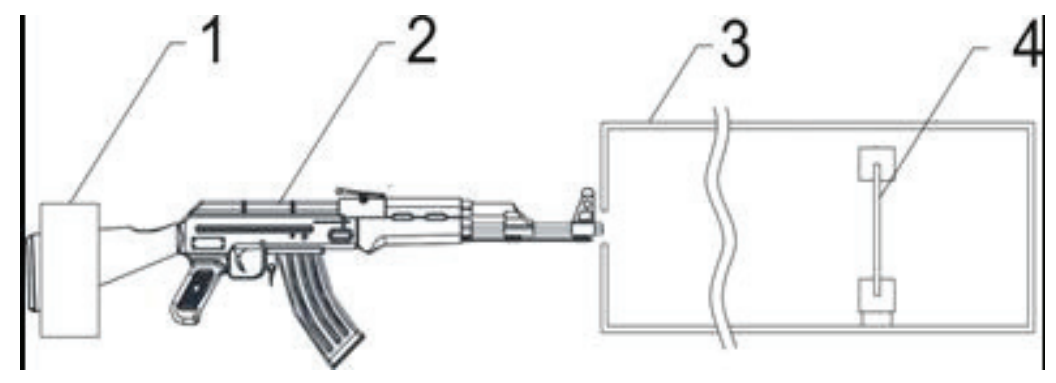

Fig. 1. Scheme of the stand for testing ballistic properties of the base materials and laminates: 1 - bracket for mounting weapons, 2 -throwing device (suitable caliber firearm), 3 - butt, 4 - the test sample mounted in a holder 
a)

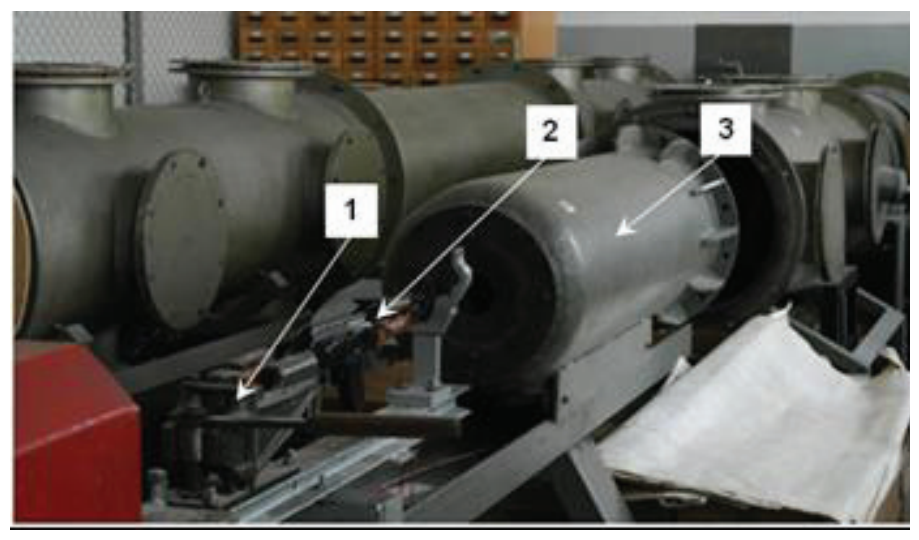

b)

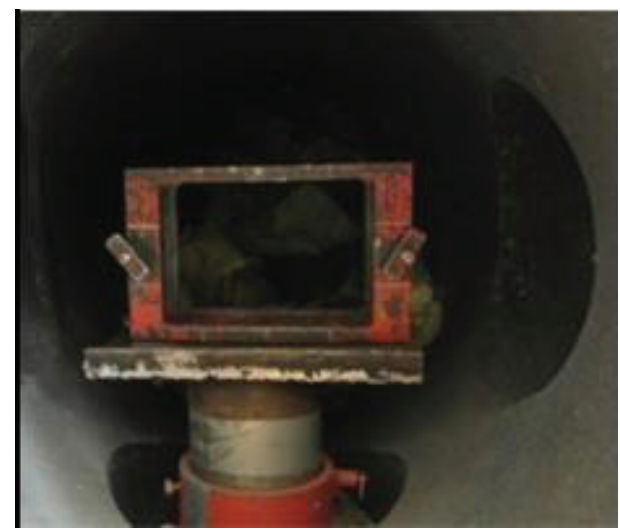

Fig. 2. The weapon mounting scheme during ballistic resistance tests (a):

1 - the start gate, 2 - struck, 3 - gate stop (b)

The ammunition used in the test

\begin{tabular}{lll}
\hline Ammunition used & Type of projectile & Velocity \\
\hline Indirect missile $-7,62 \times 39$ & BZ & $695 \mathrm{~m} / \mathrm{s}$ \\
\hline
\end{tabular}

Results of the ballistic resistance tests of the base materials provided information on the mechanisms of projectile penetration. The obtained results allowed to determine the required amount of laminates needed to stop the appropriate type of projectile. These results was used for preliminary analyzes including, among others, a comparison of the ballistic resistance of the laminates in states before and after heat treatment. Results were compared to ballistic properties of base materials as well (Fig. 3a,3b.). Specimens for tests of ballistic properties of Ti6Al4V titanium alloy were made of a colddrawn titanium rod with diameter $100 \mathrm{~mm}$ (Fig. 3c.).

a)

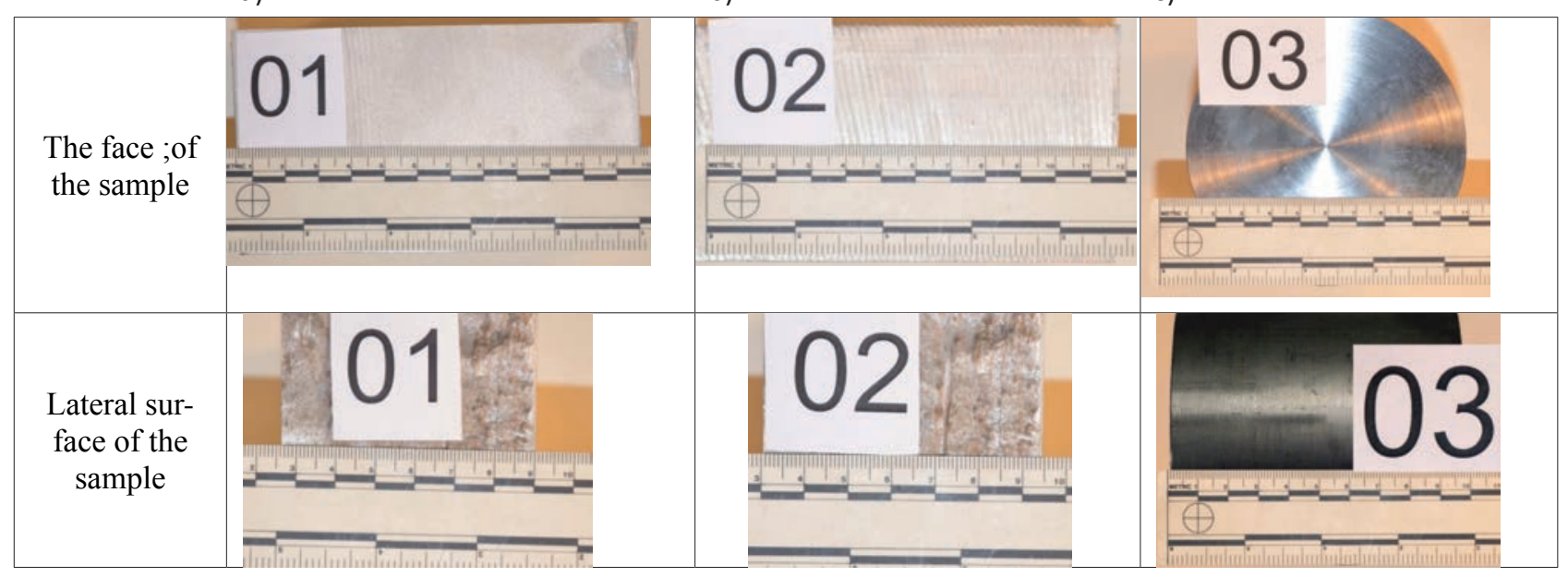

Fig. 3. Samples of base materials of the produced laminate: a) aluminum alloy AA2519 in casting form, b) aluminum alloy AA2519 in casting form after heat treatment, c) titanium alloy Ti6A14V

Each panel used for ballistic resistance test was composed of AA2519/AA1050/Ti6A14V laminates with thickness of $11 \mathrm{~mm}$. Joining of the laminate layers was performed by the method of explosive welding with the interlayer made of aluminum alloy AA1050 (thickness $0.8 \mathrm{~mm}$ ). In the first ballistic test three laminates for panel was used. The distance between the laminates was $15 \mathrm{~mm}$. In this study impact of the projectile was from the side of AA2519 layer (Fig. 4.). First results enabled to estimate the number of laminates and their thickness, necessary to avoid the perforation. 


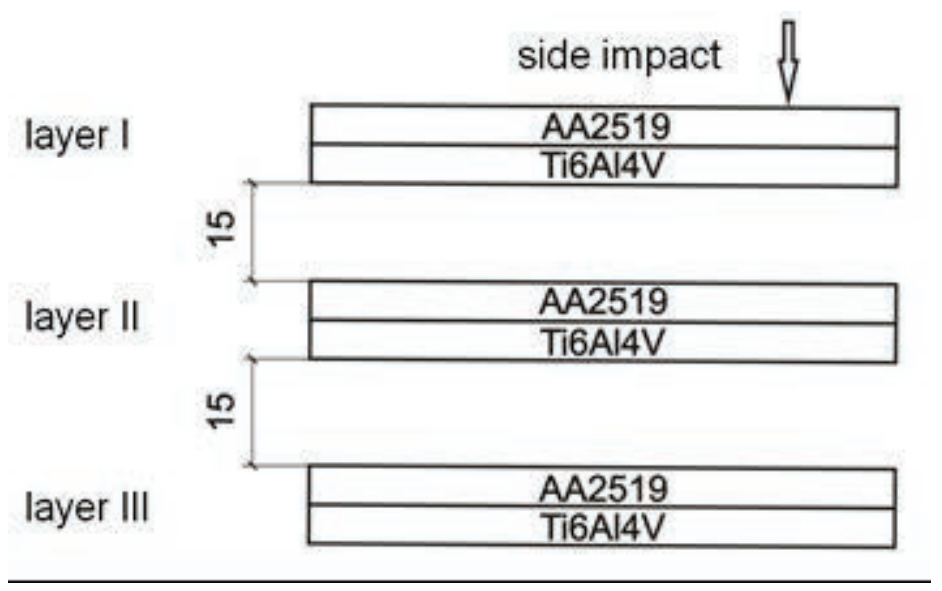

Fig. 4. Scheme of the ballistic test

Results of the first ballistic resistance tests allowed to estimate number of laminates with three different thicknesses: 3 laminates (each $10 \mathrm{~mm}$ thickness) per panel, 6 laminates (each $6 \mathrm{~mm}$ thickness) per panel and 2 laminates (each 20 mm thickness) per panel (Fig.5.). Laminates with dimensions $200 \times 120$ x thickness [mm] were selected. The presented configurations of the panels had the same mass. The obtained results allowed to choose optimal configuration of the panels with the highest ballistic resistance. In this part of study impact of the projectile was from the side of AA2519 layer and Ti6Al4V.

a)

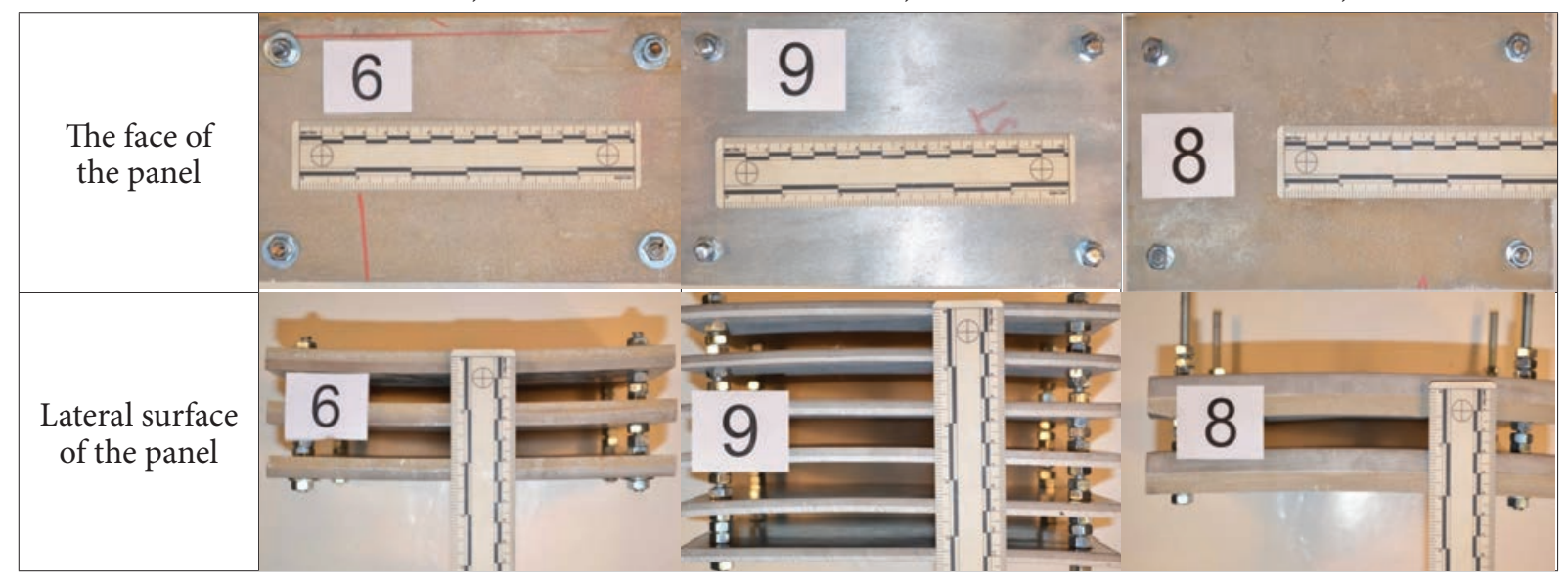

Fig. 5. Ballistic panels made of laminates: a) 3 laminates (each $10 \mathrm{~mm}$ thickness) per panel, b) 6 laminates (each $6 \mathrm{~mm}$ thickness) per panel, c) 2 laminates (each $20 \mathrm{~mm}$ thickness) per panel

\section{Results and Discussion}

\subsection{Microscopic Observation}

The cross-section of the laminate (Fig.6.) shows the bonding zones Ti6A14V/AA2519 and AA1050/AA2519. At the AA2519/AA1050 joint characteristic waves are observed. Ti6A14V/AA1050 joint is characterized by the flat surface. The wavy structure, characteristic for the joints of materials with similar densities and masses, is the result of properly selected joining parameters. In the case of a flat interface between the AA1050 and Ti6A14V alloys, its joint quality can be obtained by the formation of intermetallic zone in the form of an additional sublayer. 


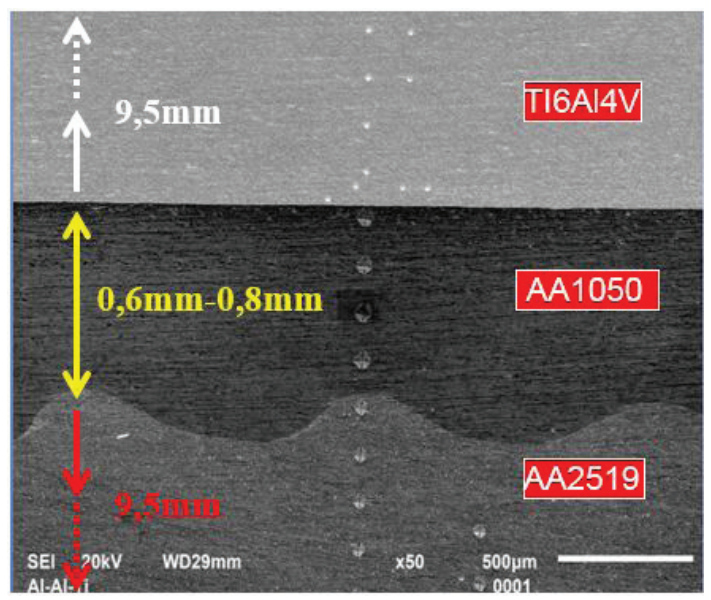

Fig. 6. Cross-section of the AA2519/AA1050/Ti6A14V laminate with the thickness of the layers

\subsection{Ballistic Resistance Test - Base Materials}

The mechanism of base materials penetration by the projectile is the same for each case. On the surface of the aluminum alloy, the inlet creates a crater with the effect of flaking resulting from the ejection of the material. Macroscopic images of the craters for AA2519 before heat treatment are shown in Figure 7a. The BZ projectile stopped in the material at a depth of $40 \mathrm{~mm}$. In the case of penetration of the material after heat treatment with a BZ projectile (Fig. 7b), an enlarged inlet resulting from the impact of the projectile is visible. The BZ projectile stopped in the material at a depth of $46 \mathrm{~mm}$. In the case of the Ti6Al4V after the heat treatment, the penetration mechanism caused numerous surface cuts in the vicinity of the hole formation (Fig. 7c).

a)

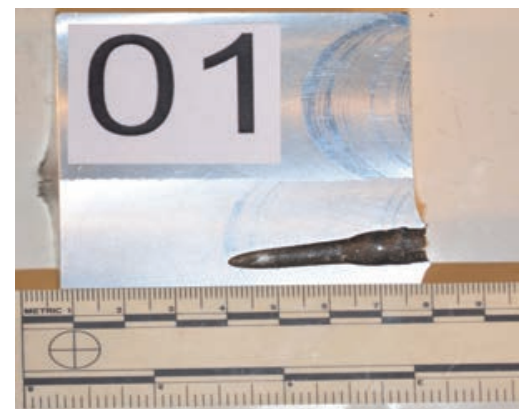

b)

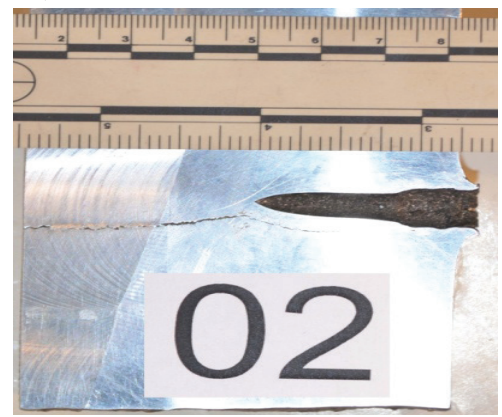

c)

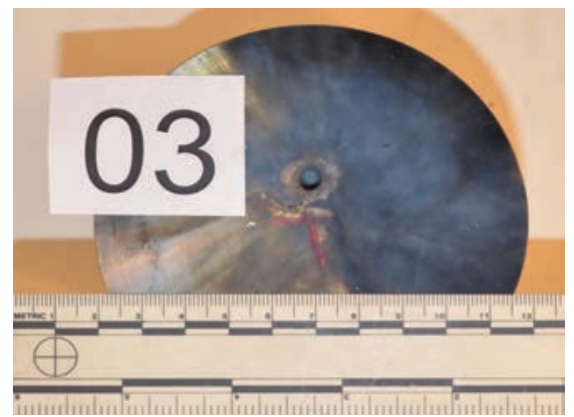

Fig. 7. Cross-section of the samples after the BZ projectile impact: a) aluminum alloy AA2519 before heat treatment, b) aluminum alloy AA2519 after heat treatment, c) titanium alloy Ti6A14V

\subsection{Ballistic Resistance Test - Panels}

The cumulative list of ballistic shield space results is presented in the Tables 5-7.

Signs:

a - overshoot

$\mathrm{x}$ - no hole

$\mathrm{a} / \mathrm{x}$ - stopped projectile, cracked layer

The ballistic resistance test results of panel Al-Ti made of 3 laminates with thickness of 10mm for each one Material before and after heat treatment

\begin{tabular}{|c|c|c|c|c|}
\hline & $\begin{array}{c}\text { side } \\
\text { shooting }\end{array}$ & 1 layer & 2 layer & 3 layer \\
\hline before a heat treatment & AA 2519 & $\alpha$ & $\alpha$ & $x$ \\
\hline after a heat treatment & AA 2519 & $\alpha$ & $\alpha$ & $\alpha / x$ \\
\hline
\end{tabular}


Impact of B32 API projectile into the $3 \times 3 \mathrm{~mm}$ panel from the AA2519 alloy side in state without heat treatment caused perforation of all three layers. The inlet of the projectile in AA2519 alloy of the first layer was formed by a shell of the projectile, which at the moment of impact in the titanium alloy swelled (Fig. 8a) and the accumulated material was located between the alloys of aluminum and titanium. The third layer did not undergo of plastic deformation and the image of the perforation of this layer indicates the occurrence of soft plugging (figure 8b).

a)

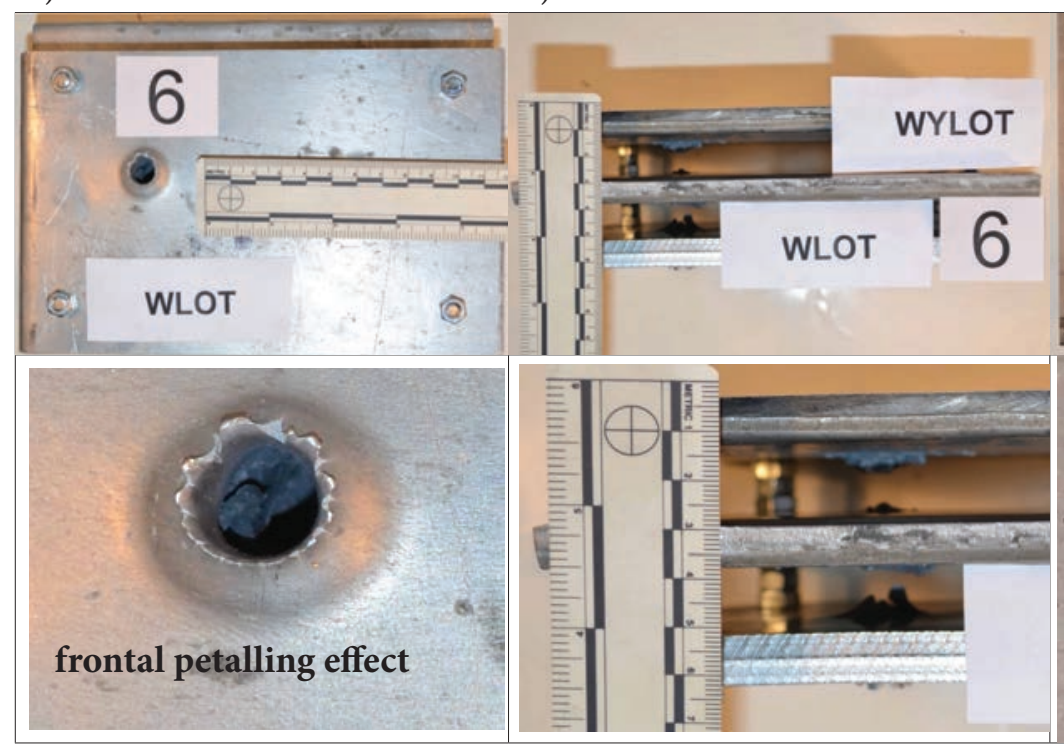

c)

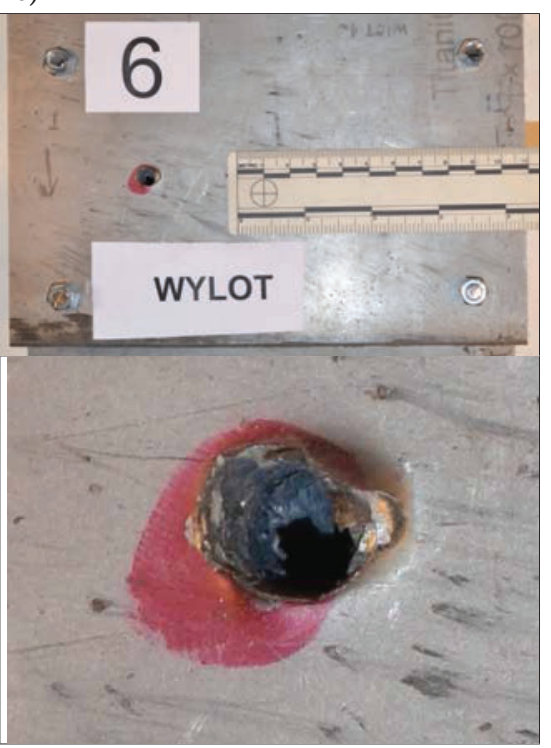

Fig. 8. Sample $3 \times 10 \mathrm{~mm}$ after the BZ projectile impact into AA2519 in state before the heat treatment, a) The face of the sample, b) Lateral surface of the sample, c) outside titanium alloy Ti6Al4V

Impact of B32 API projectile into the $3 \times 3 \mathrm{~mm}$ panel from the AA2519 alloy side in state after heat treatment also causes the penetration of all 3 layers. (Fig. 9). During the impact the first laminate of the panel was delaminated (Fig. 9b). Small crater with local loss of aluminum was visible (Fig. 9a). The third layer did not undergo of plastic deformation during its perforation. The inlet and outlet of the projectile are characterized by a circular profile (Fig. 9a,c). During the tests, it was found that the panels made of laminates in initial state exhibits higher ballistic resistance than the panels subjected to the additional heat treatment. On the last surface (Ti6Al4V) effect of material plugging was visible. The edge of the crater is jagged and sharp (Fig. 9c).

a)
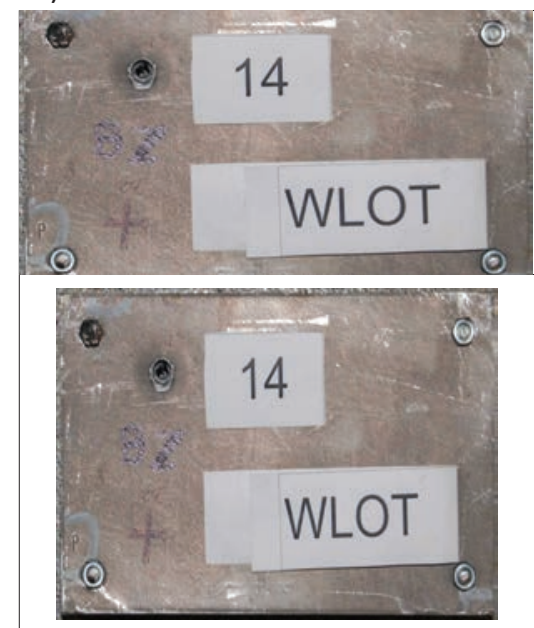

b)
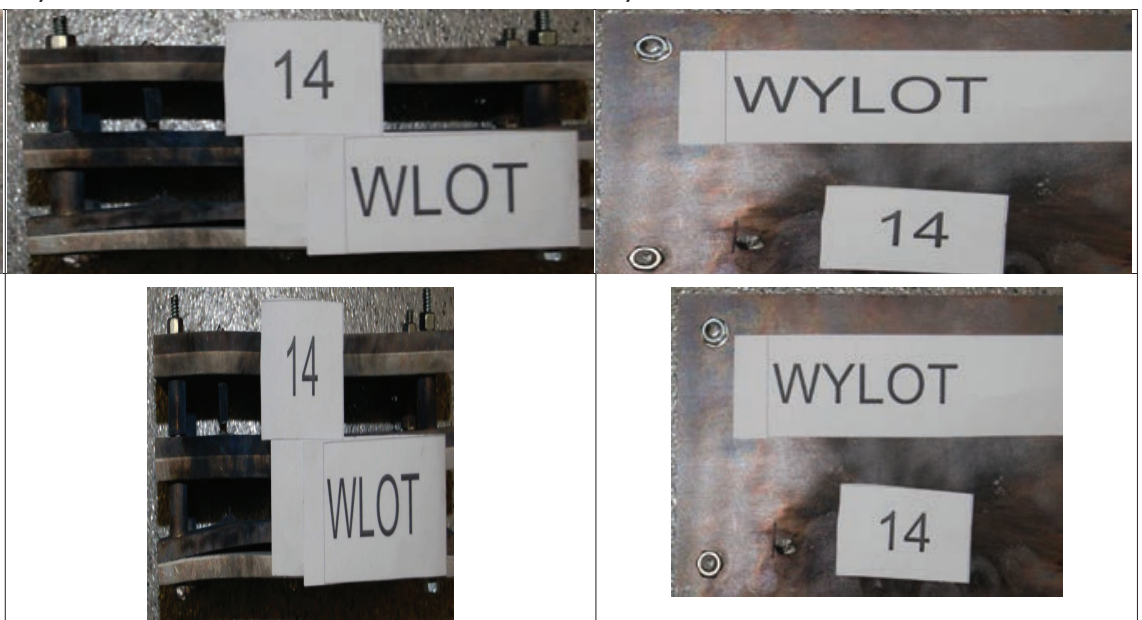

c)

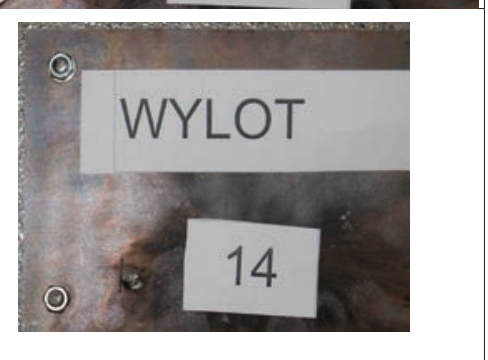

Fig. 9. Sample $3 \times 10 \mathrm{~mm}$ after the BZ projectile impact into AA2519 in state after the heat treatment, a) The face of the sample, b) Lateral surface of the sample, c) outside titanium alloy Ti6Al4V 
The ballistic resistance test results of panel Al-Ti made of 6 laminates with thickness of $6 \mathrm{~mm}$ per each one. Material before and after heat treatment

\begin{tabular}{|c|c|c|c|c|c|c|c|}
\hline & $\begin{array}{c}\text { side } \\
\text { shooting }\end{array}$ & 1 layer & 2 layer & 3 layer & 4 layer & 5 layer & 6 layer \\
\hline before a heat treatment & AA 2519 & $a$ & $a$ & $a$ & $a$ & $a$ & $\mathrm{x} / \mathrm{a}$ \\
\hline after a heat treatment & AA 2519 & $a$ & $a$ & $a$ & $a$ & $a$ & $\mathrm{x}$ \\
\hline
\end{tabular}

Figure 10 shows the effects of impact of projectile into the $6 x 6 \mathrm{~mm}$ panel by a B-32 API projectile. Impact side was from the AA2519 alloy and the laminates were in state before heat treatment. Five laminates of panel have been perforated by the projectile. The inlet of the first layer is characterized by surrounding flange (Fig. 10a). The observed type of inlet was produced by the plastic deformation of the plate forming a characteristic crater with deformed edges. In the side view of the panel (Fig. 10b), a drawn line presents a variable trajectory of the projectile's motion which is a the result of penetration of the laminates layers with different hardness. Delamination of the first laminate was observed. In subsequent layers the size of the local deformation at the point of impact of the projectile was gradually reduced. The main part of the projectile was stopped in the fifth layer, but a small part of the core performed to the sixth layer, leaving a crater with a depth equal to the thickness of the AA2519 alloy. In the vicinity of this crater single, small recesses formed after the impact of debris were observed.

a)
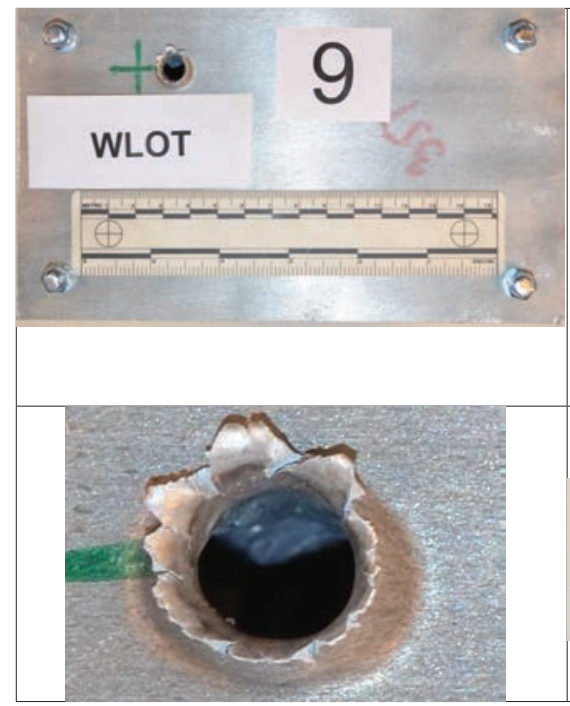

b)

c)

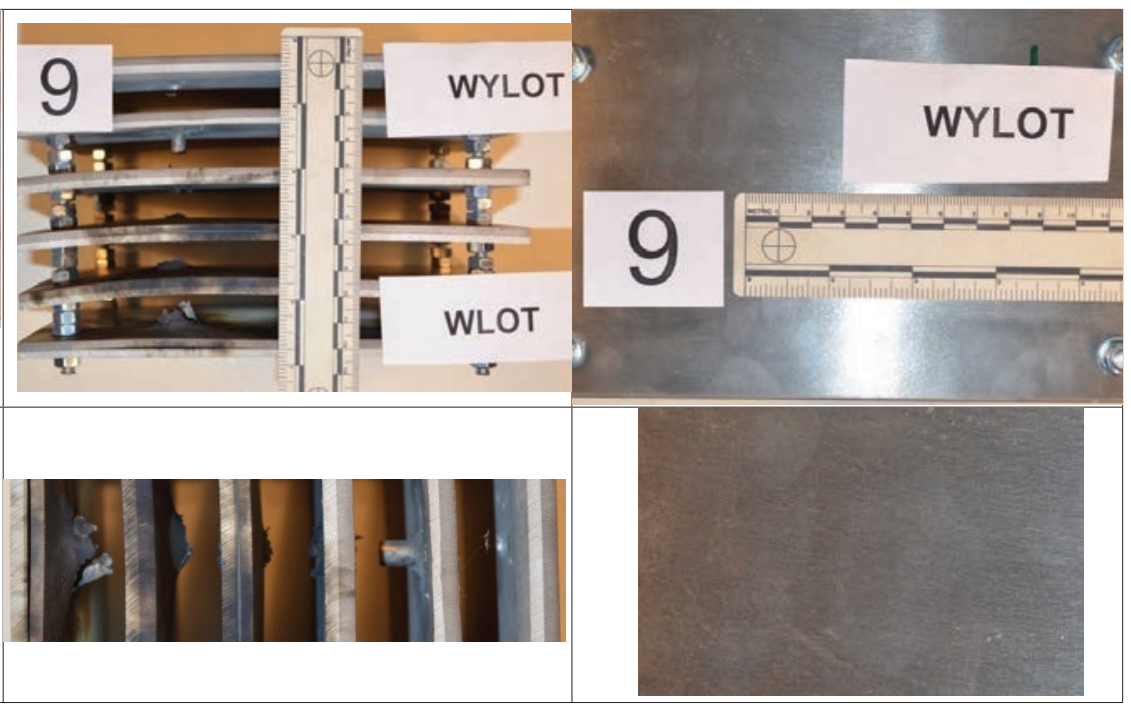

Fig. 10. Sample $6 \times 6 \mathrm{~mm}$ after the BZ projectile impact into AA2519 in state before the heat treatment, a) The face of the sample, b) Lateral surface of the sample, c) outside titanium alloy Ti6A14V

Effect of the impact into the panel in state after heat treatment is shown in Fig. 11. In the first laminate, the inlet hole has a regular outline (Fig. 11a), and its edge was formed due to plastic deformation of the AA2519 plate, caused by the dynamic impact of the projectile (frontal petalling). During the impact six laminates were perforated. The penetration does not show significant deviations from the linear trajectory of the projectile's movement (Fig. 11b). In the second laminate of the panel, as a result of the impact of the projectile, permanent deformation of the titanium alloy with simultaneous delamination of the joint was observed. The outlet of the projectile in the sixth layer has a ragged outer edge, and a zone about $15 \mathrm{~mm}$ wide from the edge of the hole has been slightly pushed out by the projectile as a results of significant reduction of its velocity. 
a)
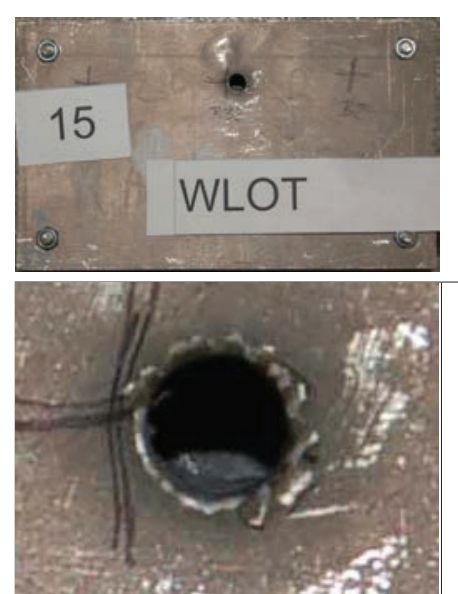

b)

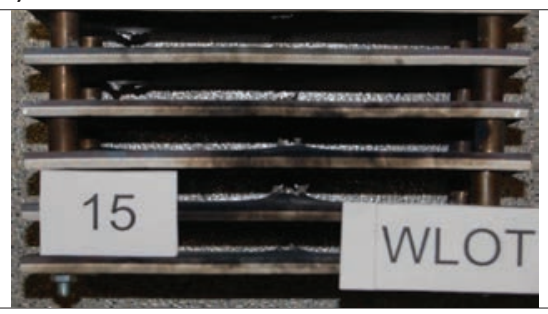

c)

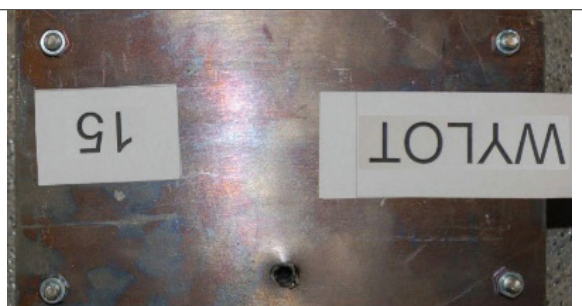

Fig. 11. Sample 6x6mm after the BZ projectile impact into AA2519 in state after the heat treatment, a) The face of the sample, b) Lateral surface of the sample, c) outside titanium alloy Ti6Al4V

Table 7

The ballistic resistance test results of panel Al-Ti made of 2 laminates with thickness of $20 \mathrm{~mm}$ per each one.

Material before and after heat treatment

\begin{tabular}{|c|c|c|c|}
\hline & $\begin{array}{c}\text { side } \\
\text { shooting }\end{array}$ & 1 layer & 2 layer \\
\hline before a heat treatment & AA 2519 & $\mathrm{a}$ & $\mathrm{x}$ \\
\hline after a heat treatment & AA 2519 & $\mathrm{a}$ & $\mathrm{x}$ \\
\hline
\end{tabular}

Figure 12 shows two-laminates panel in the state before heat treatment after projectile impact from the AA2519 side. The inlet hole in the first layer is result of the occurrence of the frontal petalling penetration mechanism (Fig. 12a). The projectile stopped in the middle of the second layer in AA2519 alloy (Fig. 12b).

a)

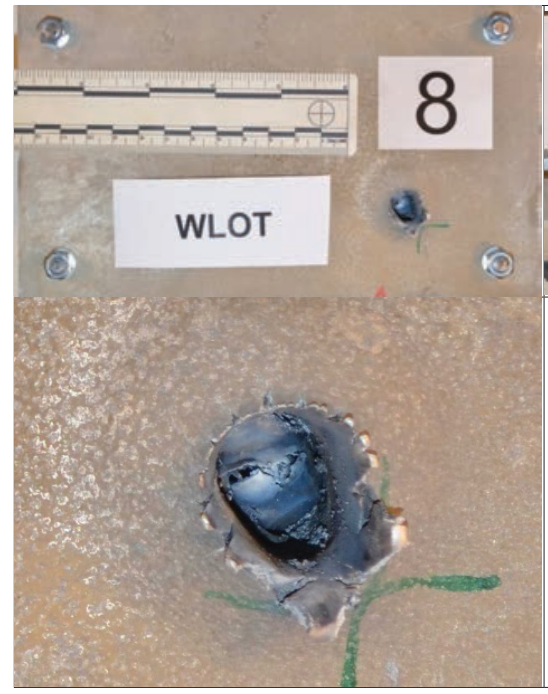

b)

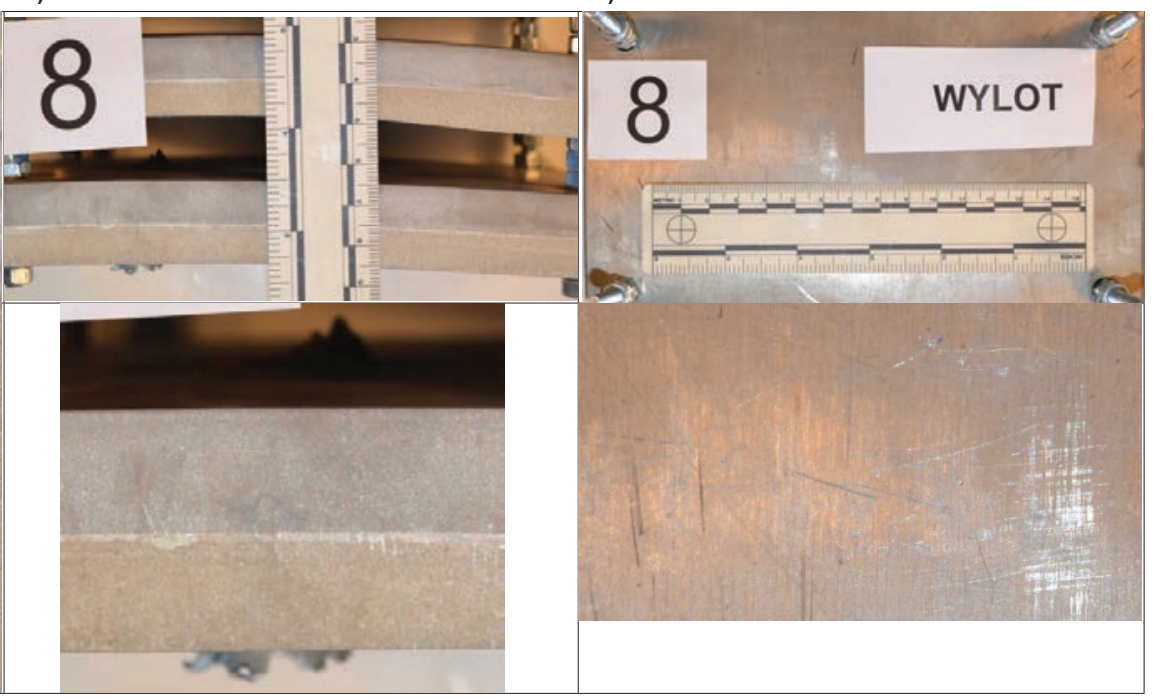

Fig. 12. Sample $3 \times 20 \mathrm{~mm}$ after the BZ projectile impact into AA2519 in state before the heat treatment, a) The face of the sample, b) Lateral surface of the sample, c) outside titanium alloy Ti6Al4V

Two-laminates panel after heat treatment impacted from the AA2519 alloy side is shown in Figure 13. In this case, the perforation of the two layers was observed. The inlet hole in the first laminate is the results of the frontal petalling penetration mechanism (Fig. 13a). In the first laminate, the presence of delamination was found. The projectile stopped in the second laminate with simultaneous fragmentation of the bullet core, which caused the plugging effect in the titanium layer (Fig. 13c). 
a)

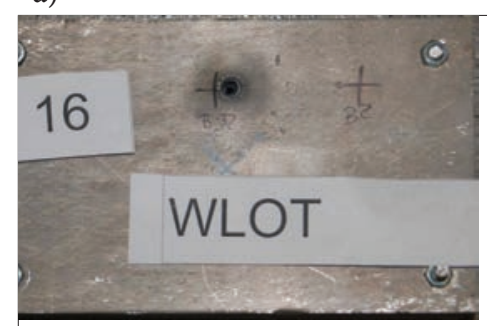

b)

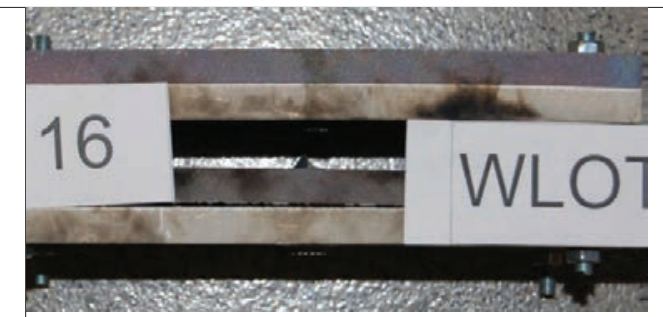

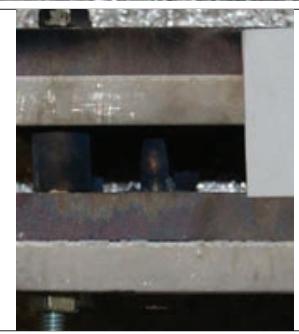

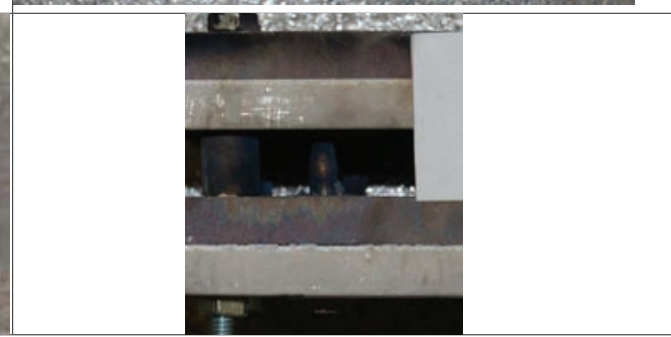

c)

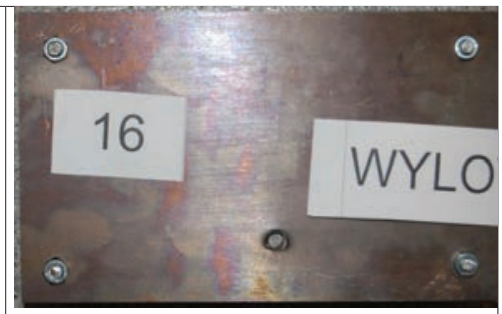

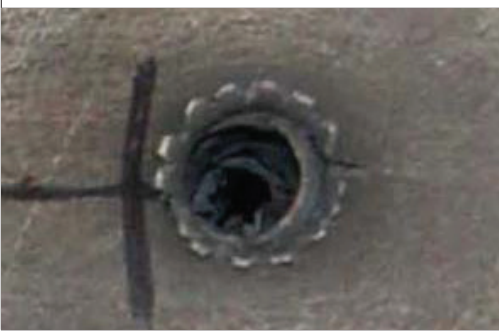

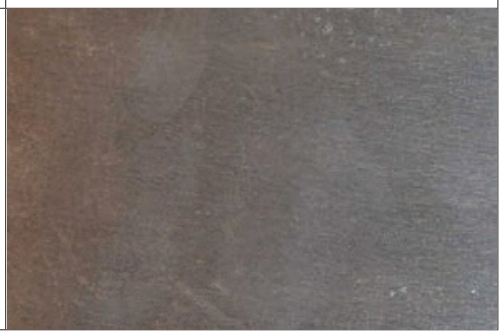

Fig. 13. Sample $2 \times 20 \mathrm{~mm}$ after the BZ projectile impact into AA2519 in state after the heat treatment, a) The face of the sample, b) Lateral surface of the sample, c) outside titanium alloy Ti6A14V

\section{Conclusions}

The experimental ballistic resistance tests were performed to estimate the applicability of the explosive welding technology in the production process of laminates made of aluminum alloys AA2519 and Ti6Al4V titanium, which could be applied as a construction materials on the ballistic shields. The field of the research included ballistic resistance tests of base materials and developed panels made of the laminates. Panel subjected to the impact of the projectile from the aluminum side is characterized by the low rate of fragmentation of the materials. Impact from the side of titanium alloy will be the subject of further research. Independently from the thickness, number of laminates and applied heat treatment, all impacted panels were perforated in a similar manner. The global deformation mode changed from a ductile hole enlargement, through a mechanism of highly localized shear around the projectile nose, to the final plugging. Plug is a part of a metallic material of the specific shape, which is sheared out from a target plate by a deformed projectile. In all cases the perforation caused fracture between the two aluminum interfaces.

\section{Acknowledgements}

The project is carried out under Project PBS2/A5/35/2013 funded by the National Research and Development Centre and PBS applied research program.

\section{References}

1. Kılıç N., Bedir S., Erdik A., Ekici B., Taşdemirci A., Güden M., Ballistic behavior of high hardness perforated armor plates against $7.62 \mathrm{~mm}$ armor piercing projectile, Materials \& Design, 2014, 63, p. 427-438.

2. National Research Council, Division on Engineering and Physical Sciences, Commission on Engineering and Technical Systems, Committee to Perform a Technology Assessment Focused on Logistics Support Requirements for Future Army Combat Systems, Reducing the Logistics Burden for the Army After Next: Doing More with Less, National Academies Press, 1999 - 224.

3. Pokorny Z.; Dobrocky D., Kadlec J., Influence of alloying elements on gas nitriding process of high-stressed machine parts of weapons, Kovove Materialy-Metallic Materials, 2018, 56 (2), p. 97-103.

4. Szachogłuchowicz I., Sniezek L., Gocman, K. The mechanical properties of composites AA2519-Ti6Al4V obtained by detonation method. - Intelligent Technologies in Logistcs and Mechatronics Systems ITELMS’2014, Proc. of The $9^{\text {tw }}$ International Conference edited by Z. Bazaras and V. Kleiza, 2013, p. 214-219 .

5. Hutsaylyuk V., Sulym H., Pasterna I., Turchyn I. Transient Plane Waves Propagation in Non-homogeneous Elastic Plate. - Composite Materials: The Great Advance. Proc. of the 19th Int. Conf. Composite Materials, ICCM19 (Montreal, Canada, 28 July - 2 August 2013), p. 8890-8897.

6. Godunov S. K., Kiselev S. P., Kulikov I..M., Mali V.I. Numerical and Experimental Simulation of Wave Formation during Explosion Welding. - Proceedings of the Steklov Institute of Mathematics, 2013, 281, p. 12-26.

7. Sniezek L., Szachogluchowicz I., Wachowski M., Torzewski J., Mierzynski J., High cycle fatigue properties of explosively welded laminate AA2519/AA1050/Ti6Al4V Procedia Structural Integrity 5, 422-429. 
8. Szachogłuchowicz I., Sniezek L., Hutsaylyuk V. Research of Property Fatigue Advanced Al/Ti Laminate. - Intelligent Technologies in Logistcs and Mechatronics Systems ITELMS'2014, Proc. of The ${ }^{\text {rm }}$ International Conference edited by Z. Bazaras and V. Kleiza, 2014, p. 232-238.

9. Slezak T., Sniezek L., A Comparative LCF Study of S960QL High Strength Steel and S355J2 Mild Steel, International Conference on Structural Integrity ICSI 2015, 114, p. 78-85

10. Lysak V.I., Kuzmin S.V. Explosive welding of metal layered composite materials / Ed. B. E. Paton. - Kiev: E.O. Paton Electric Welding Institute of NASU, 2003. - 117 p.

11. Mirjalili M., Soltanieh M., Matsuura K., Ohno M., On the kinetics of TiAl3 intermetallic layer formation in the titanium and aluminum diffusion couple, Intermetallics, 2013, 32, p. 297-302.

12. Sulym H., Hutsaylyuk V., Pasternak I., Turchyn, I. Stress-strain state of an elastic rectangular plate under dynamic load. - Mechanika, 2013, 19 (6), p. 620-626.

13. Role, S.a, Buchar, J., Hruby, V., On the ballistic efficiency of the three layered metallic targets, Proceedings - 22nd International Symposium on Ballistics 2017, p. 980-986.

14. Crouch, I.G., Greaves, L.J., Simmons, M.J., 1990. Compression failure in composite armour materials, Paper Presented at the 12th International Symposium on Ballistics, San Antonio, Texas, USA, October 1990. 